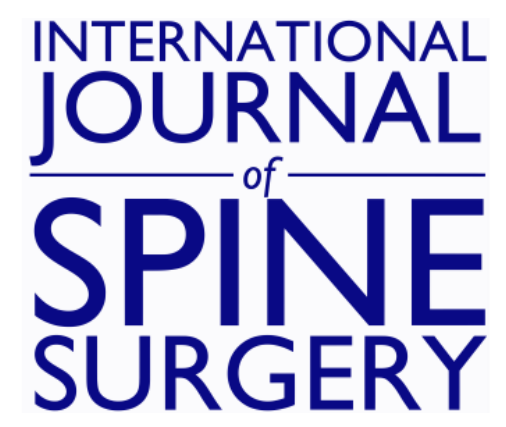

\title{
Patterns of healthcare resource utilization prior to anterior cervical decompression and fusion in patients with radiculopathy
}

Sohrab Virk, Frank M. Phillips and Safdar Khan

Int J Spine Surg 2017, 11 (4)

doi: https://doi.org/10.14444/4025

http://ijssurgery.com/content/11/4/25

This information is current as of April 26, 2023.

Email Alerts Receive free email-alerts when new articles cite this article. Sign up at:

http://ijssurgery.com/alerts

The International Journal of Shing Surgerih 2397 Waterbury Circle, Suite 1,

Aurora, IL 60504, Phone: +1-630-375-1432

(C) 2017 ISASS. All Rights Reserved. 


\section{Patterns of healthcare resource utilization prior to anterior cervical decompression and fusion in patients with radiculopathy}

Sohrab Virk MD,1 Frank M. Phillips MD,2 Safdar Khan $M D^{1}$

${ }^{1}$ Department of Orthopaedic Surgery, The Ohio State University Wexner Medical Center, Columbus, OH ${ }^{2}$ Department of Orthopaedic Surgery, Rush University Medical Center, Chicago, IL

\section{Abstract}

Objective

To assess patterns of healthcare resource utilization prior to anterior cervical decompression and fusion (ACDF) in patients diagnosed with radiculopathy with a retrospective cohort study design.

\section{Background}

ACDF is associated with improvement in quality of life among patients with cervical radiculopathy. However, little is known regarding utilization of healthcare services and total cost of care before ACDF surgery in the United States.

\section{Methods}

We analyzed a group of patients who received ACDF for radiculopathy during 2009-2011 using a healthcare database of over 20 million patients of all ages. Patients with fewer than two years of data prior to ACDF procedure were excluded. Inclusion criteria included patients with a diagnosis of disc displacement/degeneration and radiculopathy. All charges related to healthcare administration within two years prior to surgery were recorded and analyzed.

\section{Results}

Sixteen hundred seventy six patients met the inclusion criteria. Seventy-three percent of patients were in the 40-59 year age range; $55 \%$ were women and $45 \%$ were men. In the two years preceding the surgery, $34 \%$ of patients received prescription NSAIDs, and 98\% received prescription narcotics for total charges of $\$ 101,188$ ( $\$ 174.46 / \mathrm{pa}-$ tient) and $\$ 222,860$ ( $\$ 134.82 /$ patient) respectively. Total pain-related interventions over two years (oral pharmacotherapy and injections) were charged at $\$ 4,368,900$ at an average of $\$ 2,606 /$ treatment. Total outpatient charges including physician office visits, other outpatient visits and emergency room visits amounted to $\$ 25,450,012$. Mean total outpatient charges over the two years preceding ACDF was $\$ 15,556$ per patient for 26,397 episodes of care. Injectable corticosteroids were provided for $84.7 \%$ of patients and charges related to this treatment totaled $\$ 1,137$ per patient.

\section{Conclusions}

In the two years prior to ACDF, healthcare resource utilization is extremely high. Given that these patients ultimately undergo surgical intervention, opportunities to reduce charges of conservative care exist.

OTHER \& SPECIAL CATEGORIES

KEYWORDS: ANTERIOR CERVICAL DECOMPRESSION AND FUSION, RADICULOPATHY, ECONOMIC AND DECISION ANALYSIS

VOLUME 11 ISSUE 4 DOI: $10.14444 / 4025$

PAGES $201-207$

\section{Introduction}

Radiculopathy associated with degeneration of the cervical spine can lead to severe pain, limitation in function, and impaired quality of life. ${ }^{1}$ Patients with this condition frequently are treated with various medications, physical therapy as well as injection therapies. In those patients that "fail" these treatments, surgical intervention may be recommended. Anterior cervical decompression and fusion (ACDF) 
has been associated with alleviation of pain, improvement in function and overall improvement in quality of life among patients with disabling cervical radiculopathy. ${ }^{2}$ In addition ACDF has been shown to be a cost-effective intervention for this diagnosis, ${ }^{3}$ however, little is known about the utilization of healthcare services and costs of care in the period prior to ACDF surgery in the United States.

Research in the area of joint arthroplasty has shown the significant costs associated with non-operative treatment of hip and knee osteoarthritis prior to joint arthroplasty surgery. ${ }^{4}$ Berger and colleagues reported that the mean costs associated with non-surgical care averaged $\$ 9,632$ per patient over two years prior to the joint arthroplasty surgery.

Given that health care utilization in the period prior to ACDF surgery may not ultimately prevent surgical intervention, the resources consumed deserve to be analyzed. It is unknown, what proportion of patients that present with documented cervical radiculopathy will respond to non-operative treatment. An epidemiologic study of patients presenting with cervical radiculopathy reported that $26 \%$ of patients ultimately underwent surgery. ${ }^{5}$ The purpose of the current study was to measure utilization of healthcare services and direct healthcare charges in the two years prior to an ACDF procedure.

\section{Materials and Methods}

\section{Data source}

This study was exempt from our local Institutional Review Board approval. The clinical data for this study was extrapolated from a proprietary database. The PearlDiver Private Payer Database (PearlDiver Technologies, Inc., West Conshohocken, PA) is a large collection of clinical/financial information for a large body of patients. This database is composed of billing information collected by a large national private health insurance company. The goal of maintaining this database is to advance health policy research. The study cohort was found by searching Current Procedural Terminology (CPT) and International Classification of Diseases (ICD-9) codes related to more than 20 million patients of all ages. Only patients covered by commercial insurance carriers were included in this study. The relevant CPT codes included CPT 22551, 22554, 63075. The patients included were based on data between 2009 and through 2011. Both CPT 22554 and 63075 were used for ACDF procedures prior to 2011 and only CPT 22551 was used after 2011 consistent with billing codes for ACDF over those time periods. Once found, only patients who carried a diagnosis of disc displacement/degeneration and radiculopathy were included. Patients who had a diagnosis of trauma/ neoplasm were excluded in our cohort. The codes used for inclusion are listed in Table 1.

For the group of patients included within our cohort, all relevant clinical information was recorded with no patient identifiers available for study investigators. All patient identifiers in our database were encrypted. The PearlDriver database is compliant with regulations set forth by the Health Insurance Portability and Accountability Act of 1996 (HIPPA). In cases where less than 11 patients received a specific treatment or had a specific demographic characteristic, the actual number of patients was masked to protect the identity of patients. The demographic data collected included age, gender, geographical region, associated clinical diagnoses.

\section{Study sample}

Among the cohort of patients, the date of the initial ACDF procedure was designated as the index procedure date. Only patients with recorded charges throughout the two-year period prior to their index procedure were included within this study. Patients who carried a diagnosis of cervical radiculopathy and

\begin{tabular}{|c|c|}
\hline $\begin{array}{l}\text { CPT or } \\
\text { ICD-9 } \\
\text { Code }\end{array}$ & Procedure definition \\
\hline $\begin{array}{l}22551 \\
(2011 \text { pri- } \\
\text { mary code) }\end{array}$ & $\begin{array}{l}\text { Arthrodesis, anterior interbody, including disc space prepara- } \\
\text { tion, discectomy, osteophytectomy, and decompression of } \\
\text { spinal cord and/or nerve roots. Below C2 }\end{array}$ \\
\hline $\begin{array}{l}22554 \text { and } \\
63075 \text { (pri- } \\
\text { or to } 2011 \text { ) }\end{array}$ & $\begin{array}{l}\text { Arthrodesis, anterior interbody, including disc space prepara- } \\
\text { tion, discectomy, osteophytectomy, and decompression of } \\
\text { spinal cord and/or nerve roots. Below C2 }\end{array}$ \\
\hline $\begin{array}{l}723.4 \text { and } \\
729.2\end{array}$ & Radiculopathy \\
\hline $\begin{array}{l}722.2 \\
722.4 \text { and } \\
722.6\end{array}$ & Disc displacement/degeneration \\
\hline
\end{tabular}


displacement/degeneration of cervical intervertebral disc were included within this study. Relevant ICD9 codes used to identify pre-op diagnoses and relevant ICD-9 codes are shown in Table 2. Patients without the diagnoses shown in Table 2 were excluded from the study.

\section{Measures and analyses}

The demographic and clinical characteristics of each patient were examined as a group for each diagnosis. Healthcare charges over two years were analyzed on the basis of CPT codes as well as specific treatments to help assist in pain control. Total pain-related treatments were categorized as either oral, injectable or topical agents. Outpatient charges were broken down by whether or not charges were drawn from physician offices or emergency departments. In addition, charges incurred for any diagnosis within the two years prior to the index procedure were separately listed and analyzed. This included imaging, physician treatment, pharmacotherapy and other healthcare services which incurred charges from the third-party payers. These charges were not adjusted for inflation.

\section{Results}

A total of 1676 patients met the inclusion criteria. Mean age was 39.1 years. Seventy-three percent of patients were in the $40-59$ year age range; $55 \%$ were women and $45 \%$ were men. Regionally, the patients were spread throughout the country; Midwest 54.8\%, Northeast 5.8\%, South 57.6\% West 13.1\%. Preoperative associated diagnoses are listed in Table 3.

In the two years preceding the surgery, $34 \%$ of patients received prescription NSAIDs, and 98\% re-

Table 2. ICD-9 codes use to identify pre-op diagnoses related to ACDF procedure.

\begin{tabular}{|l|l|}
\hline ICD-9 & Diagnosis \\
\hline 722.2 & $\begin{array}{l}\text { Displacement of intervertebral disc, site unspecified, without } \\
\text { myelopathy }\end{array}$ \\
\hline 722.4 & Degeneration of cervical intervertebral disc \\
\hline 722.6 & Degeneration of intervertebral disc, site unspecified \\
\hline 723.4 & Brachial neuritis or radiculitis NOS \\
\hline 729.2 & Neuralgia, neuritis, and radiculitis, unspecified \\
\hline
\end{tabular}

ceived prescription narcotics. The total charges for prescription NSAIDs was $\$ 101,188$ and the total charges for prescription narcotic was $\$ 222,860$. Topical steroids were used in 77 patients $(4.5 \%$ of patients).

Total charges associated with imaging over two years were substantial. In Table 4 there is listed the charges associated with $\mathrm{x}$-rays, CT Scans and MRI

\begin{tabular}{|c|c|}
\hline Hyperlipidemia & $16.8 \%$ \\
\hline Diabetes mellitus & $8.8 \%$ \\
\hline Obesity & $6.4 \%$ \\
\hline Depressive disorders & $3.1 \%$ \\
\hline Anxiety disorders & $12.3 \%$ \\
\hline Migraine & $6.8 \%$ \\
\hline Hypertension & $29.9 \%$ \\
\hline Ischemic heart disease & $2.1 \%$ \\
\hline Valve disease & $1.0 \%$ \\
\hline Cardiac dysrhythmias & $2.9 \%$ \\
\hline Congestive heart failure & * \\
\hline Cerebrovascular disease & $1.3 \%$ \\
\hline Back pain & $43.5 \%$ \\
\hline Cervical pain & $98.7 \%$ \\
\hline Arthritis & $8.1 \%$ \\
\hline Fibromyalgia & $17.6 \%$ \\
\hline Painful neuropathic disorders & $100.0 \%$ \\
\hline Gout & $0.8 \%$ \\
\hline Other body/joint pain & $100.0 \%$ \\
\hline Other diseases of the musculoskeletal system and connective tissues & $100.0 \%$ \\
\hline Fatigue & $6.9 \%$ \\
\hline Headache & $10.8 \%$ \\
\hline Chest pain & $6.6 \%$ \\
\hline Abdominal pain & $3.6 \%$ \\
\hline Sprains and strains & $33.1 \%$ \\
\hline Dislocations and fractures & $*$ \\
\hline Sleep disorders & $6.1 \%$ \\
\hline
\end{tabular}


for pre-operative evaluation of patients. Cervical radiographs charges were $\$ 319,553$. CT Scans of the cervical spine were associated with $\$ 477,669$ in charges. Cervical MRI scans were associated with $\$ 2,877,773$ in charges.

Total pain-related charges over two years (oral pharmacotherapy including NSAIDs/Opiods and injections) totaled $\$ 4,368,900$. Oral corticosteroid charges averaged $\$ 24$ per patient for 380 patients while injection of corticosteroids was $\$ 2,720$ per patient in 1420 patients ( $84.7 \%$ of total patients). Of note, other forms of pain related interventions include antiepileptic oral medications $(\$ 158,336)$, antidepressant medications $(\$ 5,874)$, topical corticosteroids $(\$ 9,096)$ and other forms of treatment to total $\$ 4,368,900$. Total physical therapy charges were $\$ 123,135.583$ patients utilized physical therapy sessions with average charges of $\$ 211$ per patient.

Total outpatient charges, including physician office visits, other outpatient visits and emergency room visits, amounted to $\$ 25,450,012$ as listed in Table 5 . Mean total outpatient charges over the two years preceding ACDF was $\$ 948$ per treatment and $\$ 15,556 /$ patient for 26,397 episodes of care. The charges associated with "other" outpatient visits, Emergency Department (ED) or Physician office visits are listed in Table 5. Other outpatient visits refers

\begin{tabular}{l} 
Table 4. CPT Codes related to imaging for the Cervical Spine. \\
\hline CPT
\end{tabular}

to charges associated with pharmacotherapy, injections, physical therapy, chiropractor as well as any other treatment modality billed with an ICD-9 code related to cervical pathology.

The percentage of total pre-operative charges associated with various treatment modalities are listed in Table 6. NSAIDs and opiods represent a low impact on total charges associated with pre-operative care. This is in contrast to injected corticosteroids, which account for a higher portion of pre-operative charges of care.

\section{Discussion}

$\mathrm{ACDF}$ has been shown to be a cost-effective treatment for cervical radiculopathy with underlying degenerative cervical spondylosis. ${ }^{2,6,7}$ Cost effective treatments are by definition interventions that when properly indicated provide enough clinical benefit to a patient to justify the costs associated with the intervention. ACDF is typically performed after patients "fail" non-surgical treatment. There is little published data assessing the charges associated with non-operative care in patients with cervical radiculopathy. The current study quantifies the charges including charges for pain relief procedures, medications, physical therapy, outpatient clinic and emergency department visits in the two years preceding ACDF surgery. In the cohort of patients studied, utilization of resources for non-operative care in patients who ultimately underwent surgical interven-

\begin{tabular}{l} 
Table 5. Total charges in various clinical settings during the pre-operative \\
phase of treatment. These clinic visits/physician encounters were only \\
included if they were associated with a diagnosis of cervical radiculopathy \\
and/or disc degeneration. \\
\begin{tabular}{|l|r|}
\hline Outpatient Care & Charges \\
\hline Physicians' Office Visits & $\$ 7,650,440$ \\
\hline Other outpatient visits & $\$ 17,597,447$ \\
\hline Emergency Department & $\$ 202,125$ \\
\hline
\end{tabular} \\
\hline
\end{tabular}

Table 6. Charges related to pharmacologic treatment of ACDF patients.

\begin{tabular}{|l|c|}
\hline Agent & Charges \\
\hline NSAIDs & $\$ 101,188$ \\
\hline Opioids & $\$ 222,860$ \\
\hline Injected Corticosteroids & $\$ 3,862,663$ \\
\hline
\end{tabular}

Downloaded from http://ijssurgery.com/ by guest on April 26, 2023 
tion was high.

Recently concerns regarding over-utilization of narcotic medications in the United States have been raised. ${ }^{8,9}$ Our study found that $98 \%$ of patients used narcotic medications in the 2 year period prior to ACDF. Given the significant side effects and concerns for dependence, narcotics are usually reserved for patients that have severe pain non-responsive to other medications. ${ }^{10}$ The percentage of patients utilizing narcotics for radiculopathy that ultimately required surgical intervention is concerning and is substantially higher than rates reported in patients that undergo hip replacement surgery. In addition, use of pre-operative narcotic medications may predict less than optimal outcomes after surgical treatment.

A large portion of patients (84.7\%) underwent injection therapies within our cohort. Cervical ESIs have been associated with meningitis, abscess, brain and spinal cord injury. ${ }^{11,12,13}$ In addition there is data questioning the efficacy of this treatment modality for cervical radiculopathy. A recent comparativeness study did not show a significant difference in average arm pain (primary outcome measure) for patients with cervical radiculopathy between cervical ESIs and oral nortriptyline/gabapentin and physical therapy. ${ }^{14}$

Recent reforms initiated by the Affordable Care Act have focused in part on making health care delivery more efficient and cost-effective. ${ }^{15}$ This includes rewarding providers who provide high-quality care at low costs. In order to implement this, new payment models are being actively investigated. One of these proposed models utilizes bundled payments that would tie payments to the management of a specific diagnosis regardless of specific treatment selected by the provider. ${ }^{16}$ When considering a single payment for treatment of patients with cervical radiculopathy, the pre-operative charges identified in the current study will need to be accounted for and their value in the treatment continuum should be critically scrutinized.

Evidence of exhaustion of nonoperative modalities of treatment has been used by the Center for Medicare and Medicaid Services (CMS) as a prerequisite for reimbursement of providers for total joint arthroplasty. ${ }^{17}$ The value of these treatments has yet to be determined. It is reasonable to believe that surgeons will increasingly have to document appropriate nonoperative modalities of treatment prior to providing surgical care for a variety of diagnoses. The charges and timing of these nonoperative modalities of care need to be considered particularly in patients who ultimately undergo surgical intervention. The current study suggests that in a subset of patients, nonoperative care is associated with high charges. Certainly if this subset of patients could be identified, the need for these time consuming and costly treatments could be avoided.

The significant charges associated with outpatient care of patients with cervical pathology indicates that there may be utility in implementing stratified care for patients complaining of neck and arm pain. Recent research by Whitehurst et al. showed the costeffectiveness of having stratified treatment algorithms for patients at low, medium and high risk of persistent, disabling back pain. ${ }^{18}$ Research into a similar algorithm for streamlining care for patients with neck pain may help curb the significant charges associated with outpatient care. Furthermore, future research into whether or not increased pre-operative care (such as injections, prescription medications, ) enhance or reduce clinical outcomes for patients that eventually go on to have an ACDF procedure will be vital.

There are important limits to this study. Charges were only investigated in patients who had private health insurance. This database did not include patients who have care provided through Medicare and Medicaid. There have been studies implicating the significant effect of payer characteristic on medical treatment. ${ }^{19,20}$ It is currently unknown how payer type influences pre-operative charges for cervical spine pathology. Another significant limitation is that only charges from a third party payer were used to estimate the financial impact of treatments for cervical radiculopathy. It is unknown what the cost-charge ratio is for these services and therefore the reimbursement for these services is unknown. Due to the nature of medical billing, we would only be able to associate a prescription with cervical spine pathology if a

Downloaded from http://ijssurgery.com/ by guest on April 26, 2023 
cervical spine pathology related ICD-9 code was associated correctly with a prescription. This is, therefore, associated with the accuracy of medical coding and if a diagnosis is not correctly associated with a prescription than this may under or overestimate medication costs.

Due to limitations in the clinical information that can be extracted from administrative claims databases, it is unknown why our cohort of patients were treated non-operatively for two years prior to their ACDF procedure. Given that this may be an unusually high time for non-operative treatment, we may overestimate the size of charges related to non-operative treatment. These patients may have a more insidious growth in symptoms, but this subtle clinical information can't be extracted from CPT codes and ICD-9 codes alone.

This study based its findings on an administrative claims database which have been shown to have imperfect correlation with clinical records. ${ }^{21,22}$ Given the complexity of evaluating charges associated with healthcare, however, these administrative databases may be the best way to estimate charges of care for a large cohort of patients. Furthermore, hospitals and providers have a vested interest in accurately portraying charges for third-party payers in order to avoid fraud allegations and to be appropriately compensated for their work.

Physical therapy charges within this analysis totaled $\$ 123,135$ (\$211/patient).. There is, little published on the charges associated with physical therapy for many musculo-skeletal diagnoses. Ong and colleagues reported that a total of $\$ 648$ million a year were spent on physical therapy for 50,886 THA patients and 107,675 TKA patients. ${ }^{23}$ No similar study has been performed for patients with cervical spine pathology.

An area of further research that this study raises is how to identify patients who undergo ACDF but consume disproportionately more resources during the pre-surgical treatment course. Given the drive towards payment models centered around a bundled payment for an episode of care, it will be vital for payers and providers to identify patients with indica- tions for ACDF with tendencies toward higher cost of care. This might allow for the creation of modifiers for lump sum payments to more accurately reflect the patient characteristics or could lead to strategies to eliminate excessive spending in this cohort. Furthermore, future studies on the effectiveness of these non-operative modalities specifically related to the cervical spine are required. These future studies will involve determining the relative value using Quality Adjusted Life Year (QALY) analysis for treatments such as physical therapy, epidural steroid.

In summary, the charges related to nonoperative care of patients with cervical radiculopathy that ultimately undergo surgery are substantial. Physical therapy, narcotic medications, NSAIDs, injection therapies, physical therapy and other outpatient treatment modalities charge on average $\$ 15,556$ / patient in the two years prior to surgery. In the era of health care reform, attempts at creating a more efficient and higher-quality healthcare system will need to account for these significant charges associated with nonoperative treatment for patients with cervical radiculopathy who ultimately undergo definitive surgical intervention.

\section{References}

1. Saal JS, Saal JA, Yurth EF. Nonoperative management of herniated cervical intervertebral disc with radiculopathy. Spine (Phila Pa 1976). 1996;21(16):1877-1883.

2. Angevine PD, Zivin JG, McCormick PC. Costeffectiveness of single-level anterior cervical discectomy and fusion for cervical spondylosis. Spine (Phila Pa 1976). 2005;30(17):1989-1997.

3. McAnany SJ, Overley S, Baird EO, et al. The 5-year cost-effectiveness of anterior cervical discectomy and fusion and cervical disc replacement: a Markov analysis. Spine. 2014;39(23):1924-1933.

4. Berger A, Bozic K, Stacey B, Edelsberg J, Sadosky A, Oster G. Patterns of pharmacotherapy and health care utilization and costs prior to total hip or total knee replacement in patients with osteoarthritis. Arthritis Rheum. 2011;63(8):2268-2275.

5. Radhakrishnan K, Litchy WJ, O'Fallon WM, Kurland LT. Epidemiology of cervical radiculopathy. 
A population-based study from Rochester, Minnesota, 1976 through 1990. Brain : a journal of neurology. 1994;117 ( Pt 2):325-335.

6. Ament JD, Yang Z, Nunley P, Stone MB, Kim $\mathrm{KD}$. Cost-effectiveness of cervical total disc replacement vs fusion for the treatment of 2-level symptomatic degenerative disc disease. JAMA Surg. 2014;149(12):1231-1239.

7. Virk SS, Elder JB, Sandhu HS, Khan SN. The cost Effectiveness of Polyetheretheketone (PEEK) Cages for Anterior Cervical Discectomy and Fusion. J Spinal Disord Tech. 2014;24:24.

8. Shah NG, Lathrop SL, Reichard RR, Landen MG. Unintentional drug overdose death trends in New Mexico, USA, 1990-2005: combinations of heroin, cocaine, prescription opioids and alcohol. Addiction. 2008;103(1):126-136.

9. Sullivan MD, Edlund MJ, Fan M-Y, DeVries A, Braden JB, Martin BC. Trends in use of opioids for non-cancer pain conditions 2000-2005 in commercial and Medicaid insurance plans: the TROUP study. Pain. 2008;138(2):440-449.

10. Compton WM, Volkow ND. Major increases in opioid analgesic abuse in the United States: concerns and strategies. Drug and alcohol dependence.

2006;81(2):103-107.

11. Singh R, Panagos A. Quadriparesis following cervical epidural steroid injections. The spine journal : official journal of the North American Spine Society. 2006;6(3):349.

12. Papadakis CE, Chimona TS, Skoulakis CE, Prokopakis EP, Kyrmizakis DE, Velegrakis GA. Cervical prevertebral abscess owing to injection of corticosteroids. The Journal of otolaryngology.

2005;34(4):254-257.

13. Huang RC, Shapiro GS, Lim M, Sandhu HS, Lutz GE, Herzog RJ. Cervical epidural abscess after epidural steroid injection. Spine. 2004;29(1):E7-9. 14. Cohen SP, Hayek S, Semenov Y, et al. Epidural steroid injections, conservative treatment, or combination treatment for cervical radicular pain: a multicenter, randomized, comparative-effectiveness study. Anesthesiology. 2014;121(5):1045-1055.

15. Jampel HD, Cassard SD, Friedman DS, et al. Trends over time and regional variations in the rate of laser trabeculoplasty in the Medicare population. JAMA Ophthalmol. 2014;132(6):685-690.
16. Maradit Kremers H, Visscher SL, Moriarty JP, et al. Determinants of direct medical costs in primary and revision total knee arthroplasty. Clin Orthop Relat Res. 2013;471(1):206-214.

17. Chen AF, Bloomfield MR, Lichstein PM, Yates AJ, Jr., Austin MS. What is the level of evidence substantiating the medicare local coverage determinations? J Arthroplasty. 2015;30(3):356-360.

18. Minhas SV, Chow I, Jenkins TJ, Dhingra B, Patel AA. Preoperative predictors of increased hospital costs in elective anterior cervical fusions: a singleinstitution analysis of 1,082 patients. Spine J. 2015;20(15):00038-00038.

19. Doukky R, Hayes K, Frogge N, Nazir NT, Collado FM, Williams KA, Sr. Impact of insurance carrier, prior authorization, and socioeconomic status on appropriate use of SPECT myocardial perfusion imaging in private community-based office practice. Clinical cardiology. 2015;38(5):267-273.

20. Lane-Fall MB, Iwashyna TJ, Cooke CR, Benson NM, Kahn JM. Insurance and racial differences in long-term acute care utilization after critical illness. Critical care medicine. 2012;40(4):1143-1149.

21. Bozic KJ, Chiu VW, Takemoto SK, et al. The validity of using administrative claims data in total joint arthroplasty outcomes research. J Arthroplasty. 2010;25(6 Suppl):58-61.

22. Bozic KJ, Stacey B, Berger A, Sadosky A, Oster G. Resource utilization and costs before and after total joint arthroplasty. BMC Health Serv Res. 2012;12(73):73.

23. Ong KL, Lotke PA, Lau E, Manley MT, Kurtz SM. Prevalence and costs of rehabilitation and physical therapy after primary TJA. The Journal of arthroplasty. 2015;30(7):1121-1126.

\section{Corresponding Author}

Sohrab Virk, Address: $376 \mathrm{~W} 10^{\text {th }}$ Avenue, Columbus, OH 43210. Sohrab.virk@osumc.edu.

Published 1 August 2017.

This manuscript is generously published free of charge by ISASS, the International Society for the Advancement of Spine Surgery. Copyright @ 2017 ISASS. To see more or order reprints or permissions, see http://ijssurgery.com. 